An official publication of the International Society for Energy, Environment and Sustainability (ISEES)
Journal of Energy and
Environmental Sustainability
Journal homepage : www.jees.in

\title{
Treatment of Grey Water Using Horizontal Flow Constructed Wetland
}

\author{
K. Soundaranayaki \\ Centre for Environmental Studies, Anna University, Chennai-600 025, India, Tel. +919442903997
}

\section{A R T I C L E I N F O}

Received : 17 August 2017

Revised : 09 October 2017

Accepted : 15 October 2017

Keywords:

Horizontal flow constructed wetland, Canna Indica, Hydraulic Retention Time Macrophytes

\begin{abstract}
A B S T R A C T
The aim of this work was to study the pollutant removal efficiencies of two lab-scale horizontal flow constructed wetland systems treating real greywater with Canna Indica as a wetland plant. Both the wetland systems had an identical configuration. Horizontal Flow System 1 (HF1) acted as a control unit, without wetland plants whereas Horizontal Flow System 2 (HF2) acted as a constructed wetland, planted with Canna Indica. To understand the removal efficiencies of various pollutants in the greywater these systems were operated simultaneously under batch mode of flow for different Hydraulic Retention Time (HRT's) of 10, 6, and 4 days. Removal of TSS (89-95\%), BOD (70-85 \%), COD (72-80\%), $\mathrm{NH}_{3}-\mathrm{N}(32-43 \%)$, TP $(45-52 \%)$ and Surfactant $(50-56 \%)$ were obtained in the HF1 control wetland system and Removal of TSS (89-92\%), BOD (75-91\%), COD (80-95\%), NH $-\mathrm{N}$ (48-59\%),TP (49-56\%) and Surfactant $(80-83 \%)$ were obtained in the HF2 constructed wetland system . These results indicates the percentage of TSS, BOD, $\mathrm{COD}, \mathrm{NH}_{3}-\mathrm{N}$ and TP removal values are in close proximity to each other in both planted and control wetland systems. However the removal efficiency of pollutants in constructed wetland system was high, especially in the removal of surfactant when compared to the control system. Hence the macrophytes play a major role in the removal of pollutants. Similarly as the HRT increases the treatment efficiency of the constructed wetland also increased.

(C) 2017 ISEES, All rights reserved
\end{abstract}

\section{Introduction}

The constructed wetland (CWs) system is a sustainable treatment technology for treating wastewater by simulating natural wetlands, owing to lower cost, less operation and maintenance requirements, with little or no reliance on energy inputs. This system has been found to be able to remove various pollutants and nutrients from wastewater (Hammer, 1989; $\mathrm{Wu}$ et al., 2011). Constructed wetland system, mainly comprised of vegetation, substrates, soils, microorganisms and water, utilize complex processes involving physical, chemical, and biological mechanisms to remove various contaminants or improve the water quality (Vymazal, 2011; Saeed and Sun, 2012; Wu et al., 2015). Constructed wetland systems are considered as low-cost alternative for wastewater treatment, especially suitable for developing countries (Wittgren and Maehlum, 1997; Yalcuk and Ugurlu 2009). According to the wetland hydrology the constructed wetland is classified into free water surface and subsurface systems. In subsurface flow CWs water flows underneath and through the plant rooting media and water level is maintained below the tip of the substratum. Subsurface flow CWs could be classified according to the flow direction into horizontal and vertical. In the horizontal flow systems (HF), the wastewater is fed in the inlet continues its way under the surface of the bed in a horizontal path until it reaches the outlet zone. Due to a long retention time of the wastewater BOD, COD and TSS removal is possible to a high degree, normally higher then $80-90 \%$ in a HF system. In the vertical flow systems (VF), however, the wastewater is fed on the whole surface area through a distribution system and passes the filter in a more or less vertical path (Vymazal 2010; Yalcuk and ugurlu 2009).

Household wastewater can be divided into blackwater containing wastewater generated by the toilet (feces and urine) and greywater containing all other flows: from showers, bathtubs, sinks, kitchen, dishwashers, laundry tubs, and washing machines(Gross et al., 2015).It commonly contains soap, shampoo, and toothpaste, food scraps, cooking oils, detergents and hair. The amount of wastewater generated by any household will vary greatly according to the dynamics of the household, and is influenced by such factors as the number of occupants, the age distribution of the occupants, their lifestyle characteristics, water-usage patterns, the cost of water and the climate (WHO Manual).

Grey water makes up the largest proportion of the total wastewater flow from households in terms of volume. The total grey wastewater fraction has been estimated to account for about $75 \%$ of the combined residential sewage (Hansen \& Kjellerup, 1994). Hence reuse of greywater will be an effective management of grey water. There are many problems related to the reuse of untreated grey wastewater. The risk of spreading of diseases, due to exposure to micro-organisms in the water, will be a crucial point if the water is to be reused for e.g. toilet flushing or irrigation (Eriksson et al., 2002). Hence proper treatment has to be done before reuse of greywater. Sustainable, low cost, effective, onsite decentralised treatment technology is needed. The aim of this research is to provide an effective onsite treatment technology in the field of greywater treatment at a household level in developing countries.

\footnotetext{
*Corresponding Author: soundariya31@gmail.com
} 


\section{Materials and methods}

\subsection{Study area and wastewater}

The present study was conducted at the Sewage Treatment Plant (STP) located in Centre for Environmental Studies at Anna University, College of Engineering, Guindy campus, Chennai; Tamil Nadu. The wastewater was collected from residential houses at the campus and it was given primary treatment before being fed in the wetland system to avoid clogging problem.

\subsection{Configuration of the Wetland Systems}

The study was carried out in two plastic reactors (HF1 and HF2) of identical configuration of $60 \times 40 \mathrm{~cm}$ and $30 \mathrm{~cm}$ depth. Volume of the reactor was $0.072 \mathrm{~m}^{2}$. Both the reactors were filled with gravel and sand in layers- length wise. Gravel of size $15 \mathrm{~mm}$ to $20 \mathrm{~mm}$ and porosity of $50 \%$ was filled at the inlet for a length of $10 \mathrm{~cm}$. The middle layer was filled with sand of size $2-4 \mathrm{~mm}$ and porosity of $33 \%$ for a length of $40 \mathrm{~cm}$. The outlet was again filled with gravel of size $15 \mathrm{~mm}$ to $20 \mathrm{~mm}$ to a length of $10 \mathrm{~cm}$. Horizontal Flow reactor (HF1), acted as a control unit without any wetland plants. Horizontal Flow reactor (HF2) was the constructed wetland system, planted with wetland plant kalvazhai (Canna Indica) nearly 10 saplings were planted .After plantation both the wetland systems were waterlogged for fifteen days, allowing the establishment of macrophytes. An influent tank was provided to hold the greywater to be passed into the system and influent was fed through a $1 \mathrm{~cm}$ diameter pipe. A flow control valve was used to control the flow of greywater into the reactor.

\subsection{Operation and Testing}

\subsubsection{Operation}

After the establishment of the macrophytes, each wetland system was fed with 30 litres of grey water using two influent tanks 1 and 2 through the inlet valve for even distribution, and an outlet valve was provided at the bottom of the wetland system for the collection of treated water. Wastewater passed horizontally through the wetland system and the effluent was collected from the bottom of the wetlands and analyzed for TSS, BOD, COD, Ammonical Nitrogen, Total phosphate and surfactant. The same procedure was repeated for other HRT's 6 and 4.

\subsubsection{Wastewater sampling and analysis}

Initial characteristics of the greywater were studied and the results were tabulated in the Table 1. Effluents were collected from the outlet of each wetland system. In total, three sets of samples were collected for different HRT's. For each sample, the wastewater parameters such as $\mathrm{pH}$, TSS, BOD, COD, $\mathrm{NH}_{3}-\mathrm{N}, \mathrm{TP}$, and surfactant were measured using standard methods. BOD was analyzed by Winkler's method followed by titration. TSS and COD by Gravimetric method and Open Reflux titration method respectively. $\mathrm{NH}_{3}-\mathrm{N}$ by distillation followed by titration, Analyses of TP by Spectrophotometry- Stannous Chloride method. All the tests were carried out as per the APHA manual, Surfactant using Methylene blue Method (IS: 13428 - 2005 (Annex-K)

Table 1 Mean Pollutant concentration across the experimental wetland systems, \pm Standard deviations

\subsubsection{Removal efficiency calculations}

Removal efficiency calculations were based on mass balance

$$
\text { perceriluge efficiericy }-1-\frac{C_{R}}{C_{i}} \times 100 \%
$$

Table 1 Mean Pollutant concentration across the experimental wetland systems, \pm Standard deviations

\begin{tabular}{|c|c|c|c|c|c|c|c|c|}
\hline \multirow[t]{3}{*}{ Parameters } & \multirow[t]{3}{*}{ Unit } & \multirow[t]{3}{*}{ Influent } & \multicolumn{6}{|c|}{ Effluent conc. } \\
\hline & & & \multicolumn{2}{|c|}{10 DAY HRT } & \multicolumn{2}{|c|}{6 DAY HRT } & \multicolumn{2}{|c|}{4 DAY HRT } \\
\hline & & & HF1 & HF2 & HF1 & HF2 & HF 1 & HF2 \\
\hline Suspended Solids & $\mathrm{mg} / \mathrm{L}$ & $250 \pm 80$ & $13 \pm 23$ & $20 \pm 10.3$ & $25 \pm 6$ & $23 \pm 67$ & $27 \pm 0.9$ & $26 \pm 9$ \\
\hline BOD & $\mathrm{mg} / \mathrm{L}$ & $216 \pm 139$ & $33 \pm 12.2$ & $18 \pm 1.2$ & $35 \pm 18$ & $21 \pm 0.8$ & $63 \pm 34$ & $53 \pm 42$ \\
\hline $\mathrm{NH}_{3}-\mathrm{N}$ & $\mathrm{mg} / \mathrm{L}$ & $9.6 \pm 5.3$ & $5.4 \pm 3.3$ & $3.9 \pm 2.8$ & $5.8 \pm 2.3$ & $4 \pm 1.22$ & $6.9 \pm 2.3$ & $5 \pm 0.8$ \\
\hline Total phosphate & $\mathrm{mg} / \mathrm{L}$ & $13.9 \pm 6.7$ & $6.8 \pm 0.2$ & $6.1 \pm 0.9$ & $7.2 \pm 3.5$ & $6.2 \pm 3.4$ & $7.6 \pm 4.5$ & $7.1 \pm 2.9$ \\
\hline Surfactant & $\mathrm{mg} / \mathrm{L}$ & $6.5 \pm 4.5$ & $2.82 \pm 1.4$ & $1.7 \pm 0.9$ & $2.83 \pm 4.7$ & $1.79 \pm 6.7$ & $1.95 \pm 0.9$ & $3.25 \pm 1.4$ \\
\hline
\end{tabular}

Where, $\mathrm{C}_{\mathrm{i}}$ and $\mathrm{C}_{\mathrm{e}}$ are the inlet and outlet concentrations in $\mathrm{mg} / \mathrm{L}$.

Fig.1 Percentage removal efficiencies of pollutants, for both control and constructed wetland systems (a) TSS (b) BOD (c) COD (d) $\mathrm{NH}_{3}-\mathrm{N}$ (e) TP(f) Surfactant .

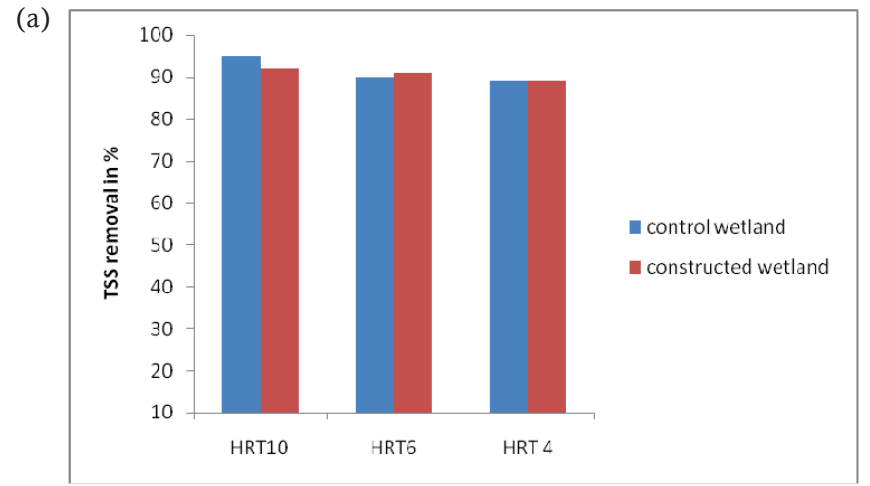

(b)

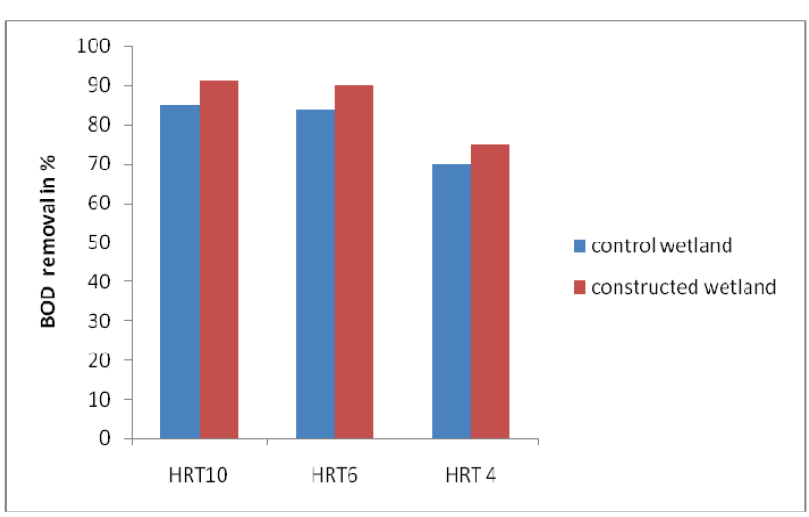

(c)

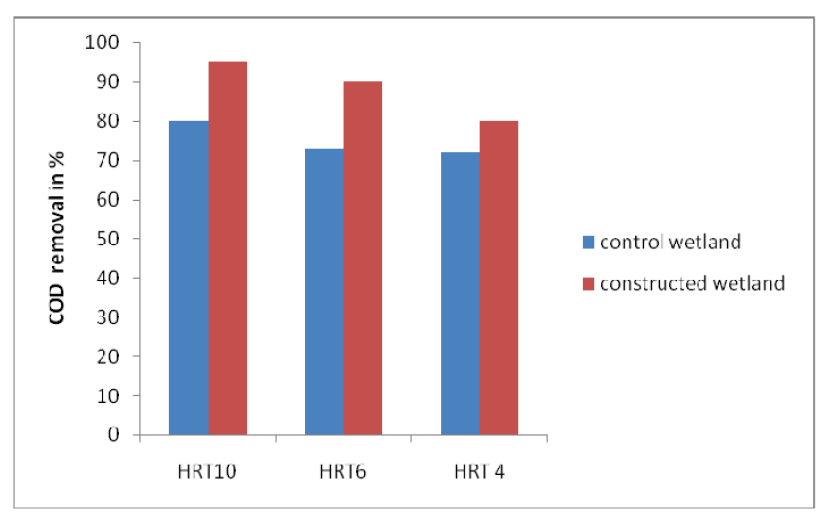


(d)

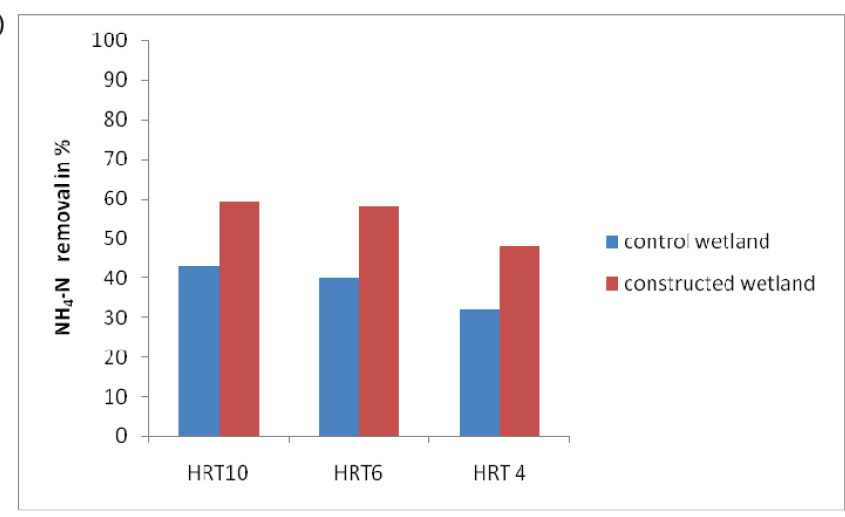

(e)

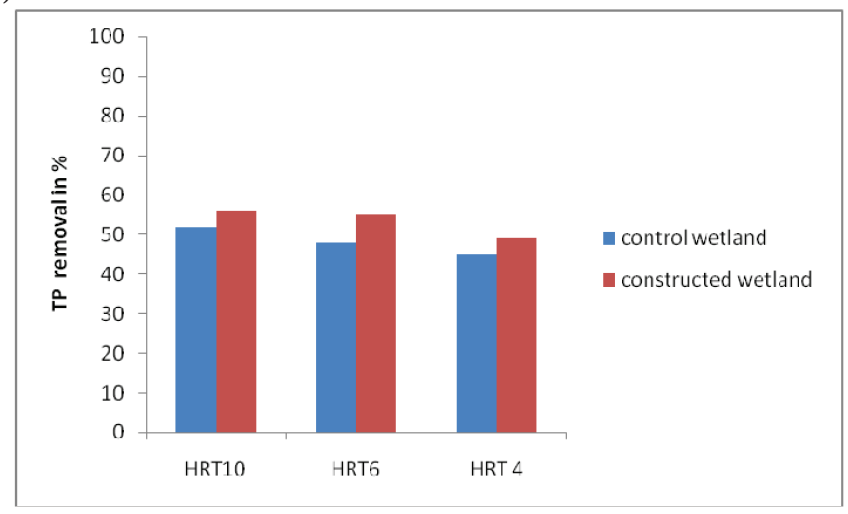

(f)

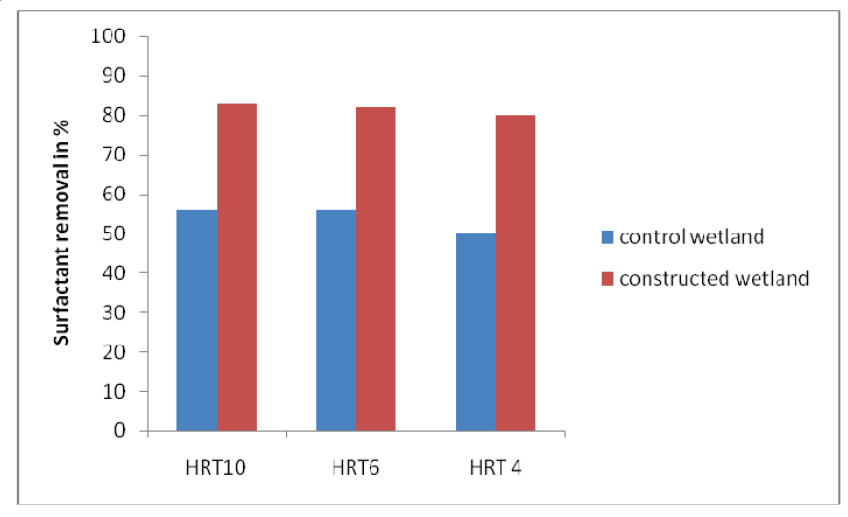

\section{Result and Discussion}

\section{$3.1 \mathrm{pH}$}

The average value of $\mathrm{pH}$ in the influent was in the range of 7-8, slightly alkaline nature. But after passing through the constructed wetland, the value of effluent $\mathrm{pH}$ decreased in both the wetlands as shown in Table 1. This indicates that there is a decomposition of organic matter which may lower the $\mathrm{pH}$ value. And also the nitrification process in the wetlands consumes alkalinity and significant nitrification can result in substantial drop of $\mathrm{pH}$ in wastewater. Such a result is consistent with the fact that significant nitrification occurs in the wetland system.

\subsection{Total Suspended Solids}

Total Suspended Solids (TSS) removal efficiencies were above $88 \%$ in both wetlands. Both wetlands show good removal percentage of suspended solids irrespective of the HRT's. As per USEPA manual (1999) TSS are removed by flocculation, sedimentation and filtration/ interception. Wetland systems are effective in TSS removal because of the relatively low velocity and high surface area in the wetland media. Wetland system act like horizontal gravel filters and thereby provide opportunities for TSS separations by gravity sedimentation, straining, physical capture, and adsorption on biomass film attached to gravel and root systems.As the TSS are predominately removed by filtration, the media -sand and gravel in the wetland bed increases the chances for the suspended solids to be trapped and retained in the bed matrices thereby improving TSS reduction.

\section{$3.3 B O D$ and $C O D$}

The percentage removal of BOD in the control wetland system was $85 \%, 84 \%$ and $70 \%$ for 10,6 and 4 HRT's respectively and for constructed wetland it was $91 \%, 90 \%$ and $75 \%$. The constructed wetland showed better removal efficiency than the control system. Wetland systems removes settlable organic compounds by filteration and deposition. Soluble organic compound are degraded aerobically or anaerobically .The oxygen supply for aerobic process is supplied by atmosphere diffusion or oxygen leakage from the roots of macrophytes. The COD removal efficiency of the constructed wetland system was $91 \%, 90 \%$ and $75 \%$ for 10,6 and 4 HRT's respectively, which was higher than control wetland system ,the macrophytes in the constructed wetland system have played a major role in oxygen supply to wetland system which is reflected in BOD and COD removal efficiency. This result indicates the macrophyes play a major role in organic compound pollutant removal mechanism.

\section{$3.4 \mathrm{NH}_{3} \mathrm{~N}$ removal}

Nitrogen removal in a constructed wetland system includes uptake by plants and other living organisms, nitrification, denitrification, ammonia volatilization and cation exchange for ammonium (Yang et al., 2001).Major nitrogen removal in constructed wetland is by microbial nitrification and denitrification process. $\mathrm{NH}_{3}-\mathrm{N}$, removal in control wetland (HF1) was 32\%-43\%, whereas in constructed wetland (HF2) it was $48 \%$ $59 \%$. Higher removal efficiency was noticed in constructed wetlands, this shows there is efficient oxygen diffusion from the atmosphere as well the plants act like snorkels, enhancing oxygen supply in their root-zones which is very essential for nitrification process. Plants root act as a attaching media for microbes. They also shade the water surface, limiting the growth of algae which would contribute to suspended solids levels in the effluent (Babatunde et al., 2009)..significant nitrification process occurs in that wetland system. The removal rate of $\mathrm{NH}_{3} \mathrm{~N}$ and subsequent drop of $\mathrm{pH}$ $\mathrm{n}$ in the effluent of this wetland system as shown in Table 1, support that $\mathrm{NH}_{3}-\mathrm{N}$ removal process was achieved via nitrification (Saeed and Sun 2011).

\subsection{Total phosphorous}

The phosphorous removal efficiency in constructed wetland may take place due to plant intake, accretions of wetland soils, microbial immobilization, retention by substrates and precipitation in the water column (Ong et al., 2009). In this study the phosphorous removal efficiency of the constructed wetlands were $56 \%, 55 \%$ and $49 \%$ for 10,6 , 4 HRT's respectively for control wetland system it was $52 \%, 48 \%$ and $45 \%$ respectively. The phosphorous reduction in the constructed wetland may be due to adsorption of some phosphorous by the gravel media and due to the plant uptake which is unavailable in control wetland system. The total phosphorous removal may slowly decrease due to saturation of the adsorption capacity of the media, hence further studied is needed to investigate the phosphorous removal or mass-balance in the constructed wetland.

\subsection{Surfactant}

Surfactant removal in constructed wetland was $80-83 \%$, but in control wetland system it was $50-56 \%$, very less compared to the constructed wetland system. The rhizosphere aeration via the constructed wetland plant roots strongly supported the anionic-surfactant removal (Síma et al., 2009). Similarly more surfactant accumulation was found in the roots of wetland sytem (Ramprasad and Ligy Philip 2015). This process was completely absent in the control system. This may be the reason for surfactant reduction in constructed wetland system.

\section{Conclusion}

Based on the above results it can be concluded that constructed wetland is an efficient treatment technique for grey water. The wetland system is efficient in removal of TSS, organic pollutant and surfactant, but the removal efficiency of ammonical nitrogen and total phosphorus is 50 $60 \%$, hence further research is needed in constructed wetland by changing media for the efficient removal of ammonical nitrogen and total phosphorus. if treated grey water is to be reused, then research can be carried on fecal coli form removal efficiency of constructed wetland. 


\section{Acknowledgement}

The author likes to thank Centre for Technology Development and Transfer (CTDT), Anna University Chennai, for funding this research work.

\section{References}

1. APHA, AWWA and WPCF Standard methods for the examination of water and wastewater, 20 th Edition, Washington, D.C; American Public Health Association, 1998.

2. Babatunde AO, Zhao Y Q, Doyle R J, Rackard S.M, Kumar JLG, Hu YS, 2011 Performance evaluation and prediction for a pilot two-stage on-site constructed wetland system employing dewatered alum sludge as main substrate, Bioresource Technology ,102 5645-5652

3. Eriksson E, Auffarth, K, Henze M, Ledin A, 2002 Characteristics of grey wastewater Urban Water 4 85-104

4. Gross A, Maimon A, Alfiya Y, Friedler E, 2015 Greywater Reuse, CRC Press Taylor \& Francis Group 6000 Broken Sound Parkway NW, Suite 300Boca Raton, FL 33487-2742

5. Hammer D.A, (Ed.), 1989. Constructed Wetlands for Wastewater Treatment: Municipal, Industrial and Agricultural. Lewis Publishers, Chelsea, MI.

6. Ong S.A, Uchiyama K, Inadama D, Yamagiwa K, 2009. Simultaneous removal of color, organic compounds and nutrients in azo dye-containing wastewater using up-flow constructed wetland. Journal of Hazardous Matter, 165, 696-703.

7. Ramprasad C, Ligy Philip 2016. Surfactants and personal care products removal in pilot scale horizontal and vertical flow constructed wetlands while treating greywater. Chemical Engineering Journal 284, 458-468.

8. Saeed T, Sun G, 2011. A comparative study on the removal of nutrients and organic matter in wetland reactors employing organic media. Chemical Engineering Journal $1712011439-447$
9. Saeed T, Sun G, 2012. A review on nitrogen and organics removal mechanisms subsurface flow constructed wetlands: dependency on environmental Parameters, operating conditions and supporting media. J. Environ. Manage.112, 429-448.

10. Síma J, Havelka M, Holcová V, 2009. Removal of anionic surfactants from wastewater using a constructed wetland. Chem Biodivers. Sep;6(9):1350-63.

11. United States Environmental Protection Agency, Constructed Wetlands Treatment of Municipal Wastewaters ,September 1999.

12. Vymazal ., 2010. Constructed Wetlands for Wastewater Treatment Water 2010, 2, 530-549; doi: $10.3390 /$ w2030530

13. Vymazal J, 2011. Plants used in constructed wetlands with horizontal subsurface flow: a review. Hydrobiology 674, 133-156.

14. Vymazal J, Brix H, Paul F,Cooper, Raimund Haberl, Reinhard and Johannes Laber 1998 Constructed Wetland for Wastewater Treatment In Europe, Pp.17-66 Edi

15. Wittgren H.B, Maehlum T, 1997. Wastewater treatment wetlands in cold climates Water Sci. Technol. 35, 45.

16. World Health Organization 2006 Overview of greywater management Health considerations

17. Wu H, Zhang J, Ngo HH, Guo W, Hub Z, Liang S, Fan J, Liu H. 2015, A review on the sustainability of constructed wetlands for wastewater treatment: Design and operation Bioresource Technology 175, 594-601

18. Wu H, Zhanga, J, Li P, Zhanga J, Xiec H, Hanga B. 2011.Nutrient removal in constructed microcosm wetlands for treating polluted river water in northern China. Ecological Engineering 37, 560-568

19. Yalcuk A, Ugurlu A, 2009. Comparison of horizontal and vertical constructed wetland systems for landfill leachate treatment. Bioresource Technology 100, 25212526

20. Yang L, Chang H.T. and Huang M.L.2001 'Nutrient removal in gravel and soil based microcosms with and without vegetation', Ecological Engineering, 18, 91105. 